\title{
Atrial fibrillation and the pituitary-thyroid axis: a re-evaluation
}

Atrial fibrillation is by far the most common important cardiac rhythm disturbance in general practice and a frequent reason for hospital referral. Cardiologists are comfortable with most aspects of patient evaluation in atrial fibrillation and with management strategies. But is measurement of serum total thyroxine (T4) and/or triiodothyronine (T3) sufficient to exclude hyperthyroidism in the clinically euthyroid patient?

It has long been known that reduced activity of the 5'deiodinase enzyme ${ }^{1}$ caused by non-thyroidal illness, such as heart failure, reduces peripheral formation of $\mathrm{T} 3$ and increases the formation of metabolically inactive reverse T3, which is not detected by the radioenzymatic assay for total T3. ${ }^{2}$ Drugs such as $\beta$ blockers and corticosteroids reduce $\mathrm{T} 3$ in a similar way; corticosteroids also reduce both T4 and T3 through a pituitary effect and aspirin and non-steroidal agents reduce $\mathrm{T} 4$ and $\mathrm{T} 3$ by displacing thyroid hormones from their plasma protein-binding sites. Furthermore, T3 concentrations fall with increasing age over 65 yet most reference ranges are derived from healthy young volunteers. The incidence of atrial fibrillation in overt hyperthyroidism ranges from $14 \%$ to $30 \%$ and increases with age. ${ }^{34}$ In hyperthyroid patients with atrial fibrillation, T3 concentrations may be within the reference range. ${ }^{5}$

Measurement of T4 alone is also unsatisfactory because a few patients present with T3 thyrotoxicosis, particularly if they have been treated for hyperthyroidism or have a nodular goitre or an autonomous thyroid nodule.

For these reasons measurement of T4 and T3 is insufficient as a screening test for the diagnosis of hyperthyroidism when cardiovascular symptoms predominate. The sensitive assays for thyrotrophin (TSH) that are now widely available ${ }^{67}$ allow low but normal TSH concentrations $(>0.1 \mathrm{mU} / \mathrm{l})$ to be distinguished from subnormal $(<0.1 \mathrm{mU} / \mathrm{l})$ or absent concentrations $(<0.01 \mathrm{mU} / \mathrm{l})$ caused by suppression of TSH secretion. These assays have largely replaced the earlier thyrotrophin-releasing hormone (TRH) stimulation test. ${ }^{8}$ The TSH-producing cells of the anterior pituitary are sensitive to minor changes in circulating thyroid hormones and absent or subnormal TSH concentrations may be found in hyperthyroid patients in whom the T3 and T4 concentrations are higher than normal for the individual but within or at the upper end of the accepted reference range. ${ }^{5}$ Thus screening thyroid function tests to exclude occult hyperthyroidism as the cause of atrial fibrillation should include total or free T3 and T4 and high sensitivity TSH measurements.

Serum sex hormone binding globulin (SHBG) is increased in hyperthyroidism and may help in the diagnosis in patients with low concentrations of TSH. SHBG does not seem to fall with intercurrent illness but is affected by liver disease, some drugs, and gonadal dysfunction and may be less useful in elderly men than in women. ${ }^{9}$ About $50 \%$ of patients with suppressed TSH have increases in SHBG, and in the presence of atrial fibrillation this may reflect the effects of thyroid hormone excess on the liver. ${ }^{10}$
Treatment of hyperthyroidism causing atrial fibrillation with specific antithyroid agents allows about $60 \%$ of patients to revert spontaneously to sustained sinus rhythm. As with other causes of atrial fibrillation, the main determinant of reversion seems to be the duration of atrial fibrillation. ${ }^{11} \mathrm{DC}$ cardioversion to sustained sinus rhythm is successful in just under half of the remaining group. Similar conversion rates to sinus rhythm appear possible after antithyroid treatment for isolated suppression of the pituitary-thyroid axis. ${ }^{5}$ The frequency of reversion to sinus rhythm is greater in those patients who become hypothyroid with six months of radioiodine treatment, presumably reflecting more rapid control of the hyperthyroid state by use of larger doses of radioiodine rather than a feature of the hypothyroid state per se which of course usually requires longterm thyroid hormone replacement. ${ }^{12}$

The sensitivity of TSH to small changes in T4 and T3 raises the question whether the pituitary is a uniquely sensitive target organ or whether changes indicative of excessive thyroid hormone production are measurable elsewhere. Doses of thyroxine that suppress TSH secretion increase nocturnal heart rate, change indices of ventricular contractile performance, increase urinary sodium excretion and serum enzyme activity from liver and muscle, decrease serum cholesterol, and increase bone resorption. ${ }^{13-16}$ All of these actions are similar to but less marked than those in overt hyperthyroidism. Although a retrospective study found no increase in morbidity or mortality in thyroxine-treated patients with a low $\mathrm{TSH},{ }^{17}$ it is reasonable to postulate that long term adverse effects can follow isolated suppression of the pituitary-thyroid axis.

An interesting recent study suggests that low TSH is also a risk factor for later development of atrial fibrillation. ${ }^{18} 2007$ clinically euthyroid subjects from the Framingham Heart Study who were over 60 years and in sinus rhythm were followed to determine the frequency of atrial fibrillation over the next 10 years. The cumulative incidence of atrial fibrillation was $28 \%$ among 61 subjects with low TSH ( $<0.1 \mathrm{mU}$ per litre) and $11 \%$ among 1576 subjects with normal values. Overt hyperthyroidism (but not atrial fibrillation) subsequently developed in two peoplle with low TSH and one with normal TSH. After adjustment for other known risk factors, the relative risk of atrial fibrillation in the subjects with low TSH was 3.1 ( $95 \%$ confidence interval 1.7 to $5 \cdot 5$ ). Two thirds (59\%) of the low TSH subjects were being treated with thyroxine replacement therapy, however, excluding these subjects had little effect on the relative risk of atrial fibrillation associated with low TSH. The mean (SD)T4 concentration was slightly higher in the low TSH group (115 (31) $\mathrm{nmol} / 1$ versus $94(22) \mathrm{nmol} / \mathrm{l})$ but was within the normal range in $84 \%$ of those not on thyroxine replacement and was not correlated with the subsequent occurrence of atrial fibrillation.

Thus it appears that subclinical hyperthyroidism (low TSH and normal T4 and T3), present over may years, is associated with long term adverse consequences for several organs, particularly the heart. The condition, however, may be transient ${ }^{19}$ and progression to overt 
hyperthyroidism is unusual. Appropriate antithyroid therapy is indicated in the presence of atrial fibrillation. If the patient is receiving thyroxine replacement therapy, the dose should be adjusted downwards to normalise the TSH concentration. It is not known whether antithyroid therapy can prevent atrial fibrillation in this situation and for most such patients a wait and see approach with follow up of thyroid function seems most appropriate.

Department of Cardiology,

J C FORFAR

Fohn Radcliffe Hospital,

Headington,

Oxford OX3 9DU

1 Kaplan MM, Utiger RD. Iodothyronine metabolism in rat liver homogenates. $\mathcal{f}$ Clin Invest 1978;61:459-71.

2 Burr WA, Griffiths RS, Black EG, Hoffenberg R, Meinhold H, Wenzel KW. Serum triiodothyronine and reverse triiodothyronine concentrations after surgical operations. Lancet 1975;ii:1277-9.

3 Sandler G, Wilson GM. The nature and prognosis of heart disease in thyrotoxicosis: a review of 150 patients treated with ${ }^{131} \mathrm{I}$. $Q \mathcal{F}$ Med 1959;28: 347-69.

4 Nordyke RA, Gilbert FI Jr, Harada AS. Graves' disease: influence of age on clinical findings. Arch Intern Med 1988;148:626-31.

5 Forfar JC, Feek CM, Miller HC, Toft AD. Atrial fibrillation and isolated suppression of the pituitary-thyroid axis: response to specific antithyroid herapy. Int $f$ Cardiol 1981;1:43-8.

6 Seth J, Kellett HA, Caldwell G, Sweeting VM, Beckett GJ, Gow SM, et al. A sensitive immunoradiometric assay for serum thyroid stimulating hormone: a replacement for the thyrotrophin relasing hormone test? $\mathrm{Br}$ Med $\mathcal{f} 1984 ; 289: 1334-6$
7 Weeks I, Sturgess M, Siddle K, Jones MK, Woohead JS. A high sensitivity immunochemiluminometric assay for human thyrotrophin. Clin Endocrinnol (Oxf) 1984;20:489-95.

8 Forfar JC, Miller HC, Toft AD. Occult thyrotoxicosis: a correctable cause of "idiopathic" atrial fibrillaton. Am 7 Cardiol 1979;44:9-12

9 Lecompte P, Lecureuil N, Lecureuil M, Osorio-Salazar C, Valat C. Age modulates effects of thyroid dysfunction on sex hormone binding globulin (SHBG) levels. Exp Clin Endocrinol Diabetes 1995;103:339-42.

10 Faber J, Gam A, Siersbaek-Nielsen K. Improved sensitivity of serum thyrotrophin measurements; studies on serum sex hormone binding globulin in patients with reduced serum thyrotrophin. Acta Endocrinol 1990;123: in patients

11 Nakazana HK, Sakurai K, Hamada N, Momotani N, Ito K. Management of atrial fibrillation in the post-thyrotoxic state. $\mathrm{Am} \not{f} \mathrm{Med} 1982 ; 72$. atrial fib

12 Scott GR, Forfar JC, Toft AD. Graves' disease and atrial fibrillation: the case for even higher doses of therapeutic iodine-131. Br Med f 1984;ii: 399-400.

13 Leslie PS, Toft AD. The replacement therapy problem in hypothyroidism Clin Endocrinol Metab 1988;2:653-69.

14 Biondi B, Fazio S, Carella C, Amato G, Gittadini A, Lupoli G, et al. Cardiac effects of longterm thyrotropin-suppressive therapy with levothyroxine. 7 Clin Endocrinol Metab 1993;77:334-8

15 Franklyn JA, Daykin J, Betteridge J, Hughes EA, Holder R, Jones SR, et al. Thyroxine replacement therapy and circulating lipid concentrations. Clin Endocrinol (Oxf) 1993;38:453-9.

16 Auwerx J, Bouillon R. Mineral and bone metabolism in thyroid disease: a review. $Q \mathcal{F}$ Med 1986;60:737-52.

17 Leese GP, Jung RT, Guthrie C, Waugh N, Browning MCK. Morbidity in patients on L-thyroxine: a comparison of those with a normal TSH to patients on L-thyroxine: a comparison of those with a normal TSH
those with a suppressed TSH. Clin Endocrinol (Oxf) 1992;37:500-03.

18 Sawin CT, Geller A, Wolf PA, Belanger AJ, Baker E, Bacharach P, et al. Low serum thyrotropin concentrations as a risk factor for atrial fibrillation in older persons. $N$ Engl $F$ Med 1994;331:1249-52.

19 Parle JV, Franklyn JA, Cross KW, Jones SC, Sheppard MC. Prevalence and follow up of abnormal thyrotrophin (TSH) concentrations in the elderly in the United Kingdom. Clin Endocrinol (Oxf) 1991;34:77-83. 